\title{
Els espais de difusió musical a la ciutat de Castelló: 1850-1880
}

\author{
RAMOn CANUt Rebull (ramonc717@gmail.com) \\ Universitat Jaume I \\ Associació Valenciana de Musicologia
}

\section{Introducció}

Per a entendre la música del segle XIX a Espanya, és important conèixer els espais on els músics vuitcentistes van desenvolupar la seua feina (Casares, 1995: 39). Durant el període decimonònic, es van produir dos fets decisius per a la professió musical: d'una banda, el procés de desamortització que va afectar l'església va fer que aquesta institució deixara de ser la principal patrocinadora de la música; d'altra, el progressiu ascens de la burgesia va comportar l'aparició d'un nou tipus de públic el qual es feia necessari captar. Per tant, al segle XIX els músics ja no estaran supeditats a les exigències d'un mecenatge nobiliari o religiós (Plantinga, 1992: 19), sinó que per assegurar-se la seua subsistència hauran de crear música per a ser interpretada als teatres públics, als cafès, als salons, etc.

Pel que fa a la ciutat de Castelló, cal destacar la seua conversió en capital provincial l'any 1833. Això va suposar per a la població la centralització administrativa i burocràtica de la província, així com l'increment dels càrrecs oficials. A més, la capitalitat va comportar també beneficis a nivell econòmic en convertir-se en el centre comercial i de serveis de la província (Aguilera, 2011: 54). En pocs anys, Castelló de la Plana va passar de tindre 14.280 habitants el 1847, a 25.193 el 1887 (Chust, 1998: 273-283). L'any 1862 arriba el primer ferrocarril i sis anys més tard es construeix el Parc Ribalta per donar la benvinguda als viatgers (Ortells, 1999: 164). Serà a partir dels anys 80 quan Castelló començarà a emergir com una ciutat important, amb un creixement econòmic basat sobretot en el sector agrícola.

Potser a causa de la presa de consciència d'aquesta capitalitat i al seu creixement demogràfic i econòmic, es crearà la necessitat i la demanda de millors infraestructures per part dels ciutadans. Entre aquestes, com veurem a continuació, la necessitat de la construcció d'un teatre digne per a la ciutat o d'una major activitat cultural i musical que ampliarà l'oferta d'espais de socialització i d'entreteniment per a l'emergent burgesia castellonenca.

\section{La música al teatre públic}

Al llarg del segle XIX la construcció de teatres a Espanya s'accelerà progressivament. A mitjans d'aquest període, tota ciutat mitjanament important havia de tindre un teatre en condicions on poder oferir als seus habitants els espectacles de moda: «A mesura que avança el segle, a totes les poblacions d'importància proliferaren els edificis teatrals i els jardins dotats d'espais teatrals; s'hi oferien fonamentalment els dos productes principals: el teatre declamat, en gran auge durant el s. XIX, i el teatre cantat» (Aviñoa, 2000: 58). Com 
comenta Solà, aquest fet va ser possible per l'esforç dels ajuntaments en la construcció i millora de locals teatrals i a l'ocupació d'edificis desamortitzats (1984: 15).

Tanmateix, la ciutat de Castelló no disposarà d'un teatre adient fins la inauguració del Teatre Principal el 15 de febrer del 1894. El local que realitzava les funcions de teatre era una casa situada al carrer Major que feia cantó amb el carrer Salinas (Mundina, 1873: 195). Bernardo Mundina ens diu que era conegut com el Teatre Vell encara que també s'anomenava Teatre del Casino Antic perquè comunicava a través d'un hort amb aquell edifici (Carreras, 1920: 38). El mateix Mundina ens fa una breu descripció i diu que: «[...] té una dolentíssima façana; el seu interior es xicotet i de regular decoració [...]».

Per aquesta causa, com bé afirma Olucha (1986: 526), en la premsa del període estudiat apareixen repetidament articles reclamant la construcció d'un teatre digne d'una capital. Un exemple d'això és l'article publicat a La Revista Castellonense el 26 de gener de 1865 :

Lo mas escogido de la sociedad castellonense se encontraba reunido en aquel antiguo templo del arte. No pudo menos de ocurrírsenos al observar esto, la grandísima necesidad que tiene esta capital, de un punto de reunion donde se pasen agradablemente las veladas, al mismo tiempo que sirva de un medio de instruccion del pueblo; la necesidad en una palabra de un teatro digno.

A mesura que avança el segle xIx s'observa com allò que era considerat com una distracció passa a ser un tema d'utilitat pública que ha de contribuir a l'augment i la difusió de la cultura. Aquesta tendència no era ignorada pels castellonencs i es troben alguns articles en la premsa que incideixen en la necessitat d'un teatre per qüestions culturals i socials. Un d'ells va ser el publicat a La Revista Castellonense el 5 de febrer de 1865:

\footnotetext{
¿Y cuando todo avanza en Castellón siguiendo el impulso civilizador actual, podia quedar estacionario y aun retrogradar en su afición al Teatro que es una de las manifestaciones mas importantes de las civilizaciones de los pueblos? ¿No es un contrasentido admitir que progresa nuestra Ciudad en toda serie de mejoras materiales, en ilustración, educación; que no va en zaga, bajo este aspecto, de poblaciones importantes de la Península, y que sólo en su afición á las funciones lirico dramáticas queda parada?
}

Tot i la precarietat de l'edifici, tal i com es remarcava al El Eco de Castellón del 18 de gener de 1857, el teatre públic era el local més important del que disposava la ciutat i s'utilitzava com un espai multiusos que s'habilitava per a realitzar tot tipus d'esdeveniments i espectacles:

Al entrar en prensa este número, bailan que se las pelan en el Teatro de la calle mayor; bien que no hay otro en la capital. -Diremos á aquellos de nuestros lectores que han preferido entregarse a los brazos de Morfeo, - ¡dichosos ellos!- lo que de notable encontremos en esta diversión.

No obstant, l'activitat teatral castellonenca es basava sobretot en les representacions dramàtiques i líriques que oferien les empreses que decidien establir-se a la ciutat. Encara que podien arribar algunes companyies especialitzades, el més habitual en aquesta època era que una mateixa companyia duguera a terme tant actuacions dramàtiques com cantades. 
En aquest sentit, l'anunci de funció publicat per La Alborada el 10 de gener de 1878 ens il·lustra sobre l'estructura que solien tindre aquestes representacions:

\author{
TEATRO PRINCIPAL \\ Funcion para hoy. $1^{\circ}$ El drama en dos \\ actos; titulado \\ LA CARETA VERDE \\ Y la zarzuela bufa en un acto, \\ ARTISTAS PARA LA HABANA \\ A las siete y media
}

Com hem dit abans, tot i no ser el més habitual en aquest període, també podem trobar-nos ocasionalment l'arribada de companyies de sarsuela. En el Diario de Castellón del 4 de novembre de 1876 es publicava la crònica d'una representació d'una d'aquestes companyies: «La compañia de zarzuela y que hace algunos dias digimos habia de llegar á nuestra poblacion, dió su primera funcion anteanoche en el local del teatro, poniéndose en escena La gallina ciega y Un caballero particular». El mateix article ens dóna informació sobre el tipus de companyies que solien vindre a la ciutat en aquells moments: «La concurrencia al teatro fué mediana, como muy mediano tambien el desempeño de las piezas».

A banda de la música lírica, el teatre públic acollia també altres tipus d'esdeveniments relacionats amb la música. Un d'ells eren els concerts instrumentals i en un article de $E l$ Centinela publicat el 18 maig de l'any 1879 s'anunciava el programa del concert en tres parts - tal i com era habitual a l'època- que va interpretar al teatre públic el guitarrista Julián Arcas:

De paso por esta capital el acreditado guitarrista don Julian Arcas dará hoy domingo en el teatro principal un concierto, ejecutando las piezas siguientes:

Primera parte.- $1 .^{\circ}$ Obertura por la orquesta. $2^{\circ}$ Gran sinfonia de la ópera Norma; arreglo del señor Arcas. $3^{\circ}$ El Paño, ó el gracioso tema popular llamado Punto de la Habana y las perteneras; del mismo.

Segunda parte.- 1 . $^{\circ}$ Piezas por la orquesta. $2^{\circ}$ Miserere del Trovador, con el final del segundo acto. $3^{\circ}$ Tanda de walses dedicados al maestro Arrieta, y pieza de sociedad.

Tercera parte. $-1 .^{\circ}$ Piezas por la orquesta. $2^{\circ}$ Serenata y marcha marcial de la ópera Fausto $3^{\circ}$ y último. Dando fin con Los panaderos, motivos flamencos y aragoneses.

Un altre tipus de concerts que es duien a terme en el teatre públic eren els concerts benèfics, com el que es va fer a la ciutat l'any 1865 per ajudar els afectats de la riuada del Xúquer. En aquest cas, és el periòdic La Crónica de Castellón del 4 de gener el que ens dóna informació al respecte, i diu que es va realitzar una vetllada dramaticolírica que en la vessant musical va comptar amb la participació d'alguns aficionats locals: «Seguidamente se presentaron en escena la señorita Doña Cristina Vera de Giner y D. Ambrosio Chillida á cantar el duo de la Traviata [...]»; al final de la vetllada es va interpretar el cor de tiples de Macbeth. En aquest període era molt difícil accedir a audicions d'òpera a la ciutat ja que 
les companyies que arribaven a Castelló només oferien sarsuela. Per això, tot i tractar-se només de fragments, aquests esdeveniments eren una bona oportunitat per escoltar aquest tipus de gènere.

\section{Les societats instructorecreatives}

Les societats instructorecreatives van ser durant aquest període un element indispensable en la vida social i cultural espanyola. No obstant, encara manca una monografia o visió de conjunt que confirme la importància d'aquestes entitats com a espais de sociabilitat musical (Alonso, 1997: 18).

La seua oferta lúdica i cultural era molt variada. Les societats instructorecreatives eren, a més de llocs de reunió i socialització, espais on es realitzaven una gran diversitat d'activitats. Ruiz de Liory (1903) recalca la importància en la dinamització musical d'aquest tipus de societats en una ciutat com València:

Contribuyó también á reaccionar las aficiones filarmónicas en la capital en los promedios del pasado siglo, la formación de una sección lírico-dramática en la sociedad titulada «El Liceo», que puso en moda las audiciones musicales é instaló un teatro en los salones de la casa social, donde se cantaron algunas óperas y zarzuelas, entre las primeras dos españolas tituladas $D$. Alfonso de Ojeda y La Esmeralda, compuestas por D. José Valero [...].

Entre els anys 1850-1880 hem identificat a la ciutat de Castelló quatre entitats que van dur a terme una activitat musical. El Liceu, la primera de les societats que hem constatat que va oferir als seus associats una programació musical, va desaparèixer abans de l'any 1860. En les dècades dels anys 60 i 70 del segle xIx, la ciutat va gaudir del dinamisme, la diversitat i la proposta cultural de quatre entitats. Així, el 15 de desembre de 1864, La Revista Castellonense treia una crònica de la inauguració del Casino Castellonense on es nomenaven les altres societats en actiu que tenia la ciutat en aquells moments:

CASINO CASTELLONENSE.- Con el competente permiso de la autoridad, procediose el domingo pasado, al nombramiento de la junta representativa de este casino. Mas de cien socios llenaban los salones de la casa en que va á instalarse la sociedad; comenzose por leer en alta voz el reglamento que ha de regir; á seguida se leyó la lista de los señores sócios componentes, resultando ser hasta la fecha, 180. Sorteáronse luego las décimas, y cada uno nombró su individuo que á su vez debe formar parte de la junta representativa. Probablemente en las próximas fiestas de Navidad tendrá lugar la inauguracion del Casino Castellonense, que vendrá á aumentar el número de centros de reunion y de recreo de esta capital. Segun tenemos entendido, mas adelante; cuando las condiciones del local lo permitan, se abrirán cátedras nocturnas, en las que se darán lecciones de diferentes ramos de ciencias con aplicación á las artes é industria.

Celebramos muchisimo este pensamiento, deseando llegue pronto la hora de ponerse en egecucion. Con este casino, contamos ya cuatro en esta capital, todos compuestos por un numero muy considerable de sócios, y que segun el orden de antigüedad son los siguientes: Casino Antiguo, Casino Nuevo, Casino de Labradores, y Casino Castellonense. 
Uns anys més tard s'inaugurava el Círculo de Artesanos amb una gran festa (La voz, 4 de setembre de 1869). Amb el Círculo, es completa el nombre d'entitats que van dinamitzar la societat castellonenca mitjançant les seues activitats lúdiques, polítiques i socials entre els anys 1850 a 1880. No obstant això, només el Liceo, el Casino Antiguo, el Casino Nuevo i el Casino Castellonense van incloure activitats relacionades amb la música.

Com hem vist anteriorment, la ciutat no disposava d'un espai apropiat per satisfer les seues necessitats culturals i musicals. Així, la creació d'aquestes entitats va fer possible l'accés a un repertori instrumental i vocal que no oferia el teatre públic. Pel que fa a la seua activitat musical, podem equiparar-la a la del teatre tant des del punt de vista qualitatiu - no n'hi ha gaire diferència entre l'oferta privada i la pública - com quantitatiu. Podem posar com exemple les representacions de sarsuela: d'un total de 171 representacions completes, 54 van ser oferides pels casinos de la ciutat. Tanmateix, si ens centrem en els anys 1850-1870, es van representar 49 funcions al teatre públic, mentre que les societats culturals van realitzar-ne 41 .

Quant al tipus d'espectacles, ens trobem els mateixos en un espai que en un altre. De la mateixa manera que passava amb el teatre, ens trobem a les societats recreatives tot tipus d'actes socials amb la presència de la música: «El Domingo y el martes, habrá bailes de máscaras en el Casino Nuevo, los que se espera que estarán tan concurridos y brillantes como en los años anteriores» (El Faro, 20 de febrer de 1873).

Pel que fa a les representacions de sarsuela, les societats recreatives complementaven l'oferta existent i, fins i tot, podien arribar a ser l'única possibilitat d'acudir a una representació. En un article d'un periòdic de l'època s'escrivia sobre la possibilitat de convertir el teatre en un magatzem de palla i garrofes, tal i com ja havia passat en altres ocasions (La Alborada, 14 de febrer de 1877). Dos dies després el mateix periòdic deia el següent: «Estamos sin compañía en el teatro principal. Gracias a que el Nuevo Casino suple ventajosamente aquella falta» (La Alborada, 16 de novembre de 1877).

La capacitat d'aquestes entitats privades per captar companyies de sarsuela es pot observar a través de l'article publicat en La Voz del Pueblo el 29 d'abril de 1869: «La del Nuevo Casino ha contratado á la compañia que actuaba en el Teatro público. Se ha abierto un abono de 6 funciones, y ya se han agotado la mayor parte de las localidades».

No obstant, va ser en l'oferta concertística on més van destacar les societats culturals castellonenques en comparació al teatre públic. Si als anys 60 començava a Madrid la instauració d'unes societats que impulsarien la música simfònica i de cambra a Espanya, l'any 1863 es creava la Sociedad Artístico-Musical de Socorros y Mutuos que tenia com a objectiu la celebració de vetllades musicals per a recaptar fons i destinar-los als músics més necessitats (Vidal i Torrent, 2006). Pel que fa a Castelló, El Centinela Federal de l'11 d'abril de 1873 parla d'una Societat Filharmònica: «La Sociedad Filarmónica dedicada por ahora á dar conciertos, vé aumentar de dia en dia sus listas de suscricion, habiendo tenido necesidad su Junta directiva, de suspender la admision hasta despues del próximo concierto, que será el segundo de su programa».

No hem trobat més informació al respecte d'aquesta societat durant el període 18501880. El que sí que apareix reflectit a la premsa són els concerts que van oferint els diferents casinos ubicats en la ciutat, els quals col-laboren en la dinamització de l'activitat musical de Castelló fent arribar un repertori d'obres instrumentals al públic castellonenc. Un exemple 
del que acabem de comentar és el concert de piano que es va dur a terme el 30 de setembre de l'any 1876 (Diario de Castellón) al Casino Antic:

Hace dias anunciamos á nuestros lectores, la próxima llegada á esta capital del reputado concertista de piano D. Oscar Camps y Soler, y hoy podemos comunicarles que se halla entre nosotros, y que esta noche dará un concierto en los salones del casino Antiguo.

Ejecutará las siguientes piezas:

1. ${ }^{\circ}$ Gottschalk.- Parafrasis de conciertos sobre el Miserere del Trovador.

$2^{\circ}$. Ketlerer.- Gran galop de concierto.

3. ${ }^{\circ}$ Camps.- Gran fantasia sobre Rigoleto.

4. ${ }^{\circ}$ Herz.- Sexto concierto.

5. ${ }^{\circ}$ Prudent.- Transcripcion de conciertos sobre Puritanos.

6. ${ }^{\circ}$ Goria.- Gran fantasia sobre Lucrezia.

Tot i que trobem altres concerts instrumentals, com el realitzat al Casino Nou pel fagotista Nereo Agostini (La Voz del Pueblo, 4 d'abril de 1869), els arranjaments de fragments d'òpera en versió concert eren els més habituals. Per a veure una representació d'òpera, els castellonencs s'havien de desplaçar a València; per tant, l'única forma d'accedir al gènere operístic per part del públic aficionat de la població era amb el format de concert com el que s'anunciava a La Revista Castellonense el 9 de novembre de 1865:

CONCIERTO.- Esta noche cantará en el Casino Castellonense, el artista italiano D. Juan Bautista Garully, las piezas siguientes:

1. ${ }^{\circ}$ Aria de Hernani, del maestro Verdi.

2 . $^{\circ}$ Romanza de la ópera Marta, de Flottou.

3. ${ }^{\circ}$ Gran aria final de Lucía di Lamemoor, de Donizetti.

4. ${ }^{\circ}$ Ballada de El Rigoletto, de Verdi.

5. ${ }^{\circ}$ Romanza de El Faust, de Gounod.

6. ${ }^{\circ}$ Romanza Un addio, compuesta espresamente para el mismo Garully.

\section{La música domèstica}

La música de saló, hereva del segle xvIII i amb un clar perfil aristocràtic, constitueix un model a imitar per la burgesia en un intent d'elevar la seua categoria social (Casares, 1995: 41). En realitat es tractava de reunions - la música era una activitat més juntament a altres activitats com la tertúlia o el joc de cartes- que pretenien distraure els assistents durant unes hores a la nit.

Pel que fa a Castelló, i a causa de la dificultat per trobar aquest tipus de fonts, no podem afirmar que es tractava d'una pràctica habitual. Tot i això, trobem alguns articles com l'aparegut el 9 de gener del 1870 a El Hermano Bartolo on es va publicar una crònica d'una reunió que es va dur a terme en casa dels senyors Martí:

Se ejecutaron varias y escojidas piezas, entre las que recordamos una fantasia al piano, sobre motivos de Roberto el Diablo de Ascher, por el Sr. Martí (D. Antonio); trio fantástico sobre 
motivos de la Lucia, de violin, violoncello y piano, por el distinguido profesor D. Francisco Gonzalez Chermá, y Segarra. Brillante fantasía del maestro Leybach sobre motivos de la Norma, por la señorita Enriqueta Milian. Galop al piano de Kettener, por la señorita Margarita Lacy, Rondó final del Relisario por doña Adela Galindo de Casaes.

La Pepita Madramany tocó al piano una magnifica fantasia de Ascher. Es esta preciosa niña una profesora, á quien se oye siempre con mucho gusto.

Las señoritas que asistieron a la reunion cantaron unos coros romanza y concertante, composición del Sr. Martí, que causaron mucho efecto y que fueron ejecutados con mucha precision é inteligencia.

No és un fet casual la presència femenina en aquestos concerts: estava ben considerat que les filles de les classes acomodades, alliberades de les tasques domèstiques, reberen una formació musical que els aportava un reconeixement i un protagonisme dins de l'alta societat.

\section{Els cafès}

Si el saló és l'espai reservat de les classes acomodades, el cafè és la seua variant oberta destinada a l'aficionat socialment més baix. Per tant, el cafè és un lloc on s'anava, a més de consumir, a escoltar a relacionar-se, participar en alguna tertúlia i escoltar música. A l'Espanya decimonònica ens trobem tres variants de cafès: el cafè cantant, el cafè teatre i el cafè líric (Casares, 1995: 45).

Una de les variants que ens trobem a la ciutat de Castelló és el cafè teatre. Quina podria haver estat la tipologia d'aquests llocs és descrita per Solà-Morales (1984: 77) en un article sobre l'arquitectura teatral espanyola: «La seua entrada arriba a coincidir amb el propi portal de la finca i la necessitat de proporcionar salons per al públic obliga a situar-los en primera $\mathrm{i}$ segona plantes, ocupant la baixa amb un cafè que fa les tasques de lloc de descans i espera».

Així, amb un espai potser semblant a la descripció anterior i amb la funció de donar accés a la música als sectors socials menys benestants de la ciutat, el teatre cafè castellonenc va tindre una bona acceptació per part del públic castellonenc: «El café-teatro continua llamando la afluencia del público. La companyia se esfuerza presentando funciones nuevas á la par que muy bien desempeñadas [...]» (El Centinela Federal, 26 de maig de 1872).

Un altre dels locals que oferia periòdicament concerts al públic assistent era el Café del Progreso. En la secció Diversiones Públicas de la Revista Castellonense del 22 de gener de 1865 apareixia el següent anunci: «Hoy de 7 á 10 de la noche, el profesor de guitarra don José Díaz, ya ventajosamente conocido del público, dará en el mismo, una pequeña funcion en la que tocará en dicho instrumento las piezas siguientes [...]».

\section{La música a l’aire lliure}

Un dels espais on era més igualitari l'accés a la música eren els passejos. Convé recalcar la importància d'aquests concerts, ja què per a una part de la població castellonenca, i en tractar-se d'una interpretació en un espai obert i públic, aquesta era l'única forma que tenien d'accedir a una audició musical. 
Ja hem comentat anteriorment que durant el segle XIX la burgesia busca crear espais propis de socialització. Així, el passeig, a més d'un lloc físic, esdevindrà una manera de relacionar-se entre iguals sota unes normes definides, mostrar-se davant la societat i començar el joc de relacions entre els joves de diferent sexe (Ferrer, 2012). La funció de la música era amenitzar el passeig aportant la banda sonora de l'esdeveniment social. A la premsa del període estudiat podem trobar molt sovint anuncis de programa com el següent (La Alborada: 15 de juliol de 1877):

A la reconocida galanteria del señor. M. Guiraoz, músico mayor del regimiento infantería de Burgos debemos el siguiente programa de las piezas que ejecutará su música durante las horas de paseo esta noche en Ribalta.

1. ${ }^{\circ}$ Radames: Paso - doble sobre motivos de la ópera Aida

2. ${ }^{\circ}$ Contradanzas americanas

3. ${ }^{\circ}$ Los cantares de España: Gran poutpourri de aires españoles

4. ${ }^{\circ}$ Schotis con variaciones de bombardino y saxofón.

En el darrer terç del segle XIX Castelló inicia el seu camí cap a la industrialització. L'any 1862 arriba el ferrocarril a la ciutat amb la inauguració del tram València-Sagunt-Castelló. Dos anys després es construeix el Parc Ribalta: «És al 1868 quan l'Ajuntament decideix al solar que ocupà l'antic cementiri municipal del Calvari, un passeig que portaria el nom del pintor Ribalta, [...]» (Vidal, 1996: 164). A partir d'aquest moment, el lloc on es realitzaran la major part de concerts de les diferents bandes militars o civils serà el templet d'aquest parc. Sobre la popularitat que va anar assolint el nou passeig Ribalta entre les classes altes de la ciutat s'escrivia a La Alborada (22 de juliol de 1877):

Cada noche se ve mas concurrido el paseo de Ribalta, siendo en la actualidad, el punto donde la buena sociedad castellonense parece darse cita los jueves y domingos para disfrutar del fresco y aromático ambiente, oyendo tocar las brillantes músicas de los cuerpos de la guarnicion de esta capital. El programa de las piezas que en las horas de paseo ejecutará esta noche la música del regimiento de Burgos, es el siguiente:

1. ${ }^{\circ}$ Paso-doble aleman: Muthig Voran: Voran.

2. ${ }^{\circ}$ Quadrile: Le Pere Simon.

3. ${ }^{\circ}$ Aria de tenor de la ópera: I Due Foscari.

4. ${ }^{\circ}$ Tanda de walses sobre motivos de la zarzuela Barba Azul.

5. ${ }^{\circ}$ Mazurca de lira: Consuelo.

Encara que el Parc Ribalta esdevindrà el passeig més important de la ciutat, La Protesta (24 de maig de 1871) ens parla d'un altre espai amb la mateixa funció:

El jueves y domingo tuvimos la satisfaccion de oir en el paseo del camino del mar los armoniosos acordes de la brillante música del regimiento de Granada, que se halla de guarnicion en esta ciudad. Damos las gracias á sus oficiales por la galanteria y amabilidad con que accediendo á nuestros deseos, proporcionan al público castellonense ratos de solaz y recreo, mucho mas agradecidos por la carencia de distracciones. 
Esporàdicament, trobem també concerts oferts per la banda municipal. En el següent anunci publicat el 9 de juliol de 1865 a La Revista Castellonese podem observar també la classe de repertori que es solia interpretar en aquest tipus de concerts: d'una banda, la música de ball de moda en l'època, i d'altra, arranjaments d'òpera o sarsuela.

MÚSICA.- La banda municipal tocará esta noche en la plaza de la Constitucion, las piezas siguientes:

1. ${ }^{\circ}$ Paso doble.

2. Terceto de Hernanni.

3 . Polka alemana.

4. ${ }^{\circ}$ Polka el Beso.

5. ${ }^{\circ}$ Cuarteto de Rigoletto.

6..$^{\circ}$ Tanda de walses.

7. ${ }^{\circ}$ Polka de los ruiseñores.

8. ${ }^{\circ}$ Habanera.

$9 .^{\circ}$ Otra habanera.

10. ${ }^{\circ}$ Batalla de Peracams.

\section{Conclusions}

Una de les claus per a entendre la música del segle XIX són els espais on es van desenvolupar les actuacions musicals. El procés desamortitzador i l'ascens de la burgesia van provocar la desaparició dels espais on la majoria de músics exercien la seua professió. Així, la ciutat de Castelló, immersa en les transformacions socioeconòmiques per eixir de l'Antic Règim, també va patir canvis en la vessant cultural i musical.

Pel que fa als llocs on es desenvolupaven les actuacions musicals, la població va comprendre des del començament la necessitat de disposar d'un teatre digne que cobrira les necessitats culturals i de socialització de l'emergent burgesia castellonenca. Tanmateix, Castelló de la Plana no disposarà d'un teatre en condicions fins a l'any 1894 i el que havia de ser l'espai musical més important de la ciutat no era més que un edifici precari i insuficient.

Igual que passava en altres ciutats d'Espanya, a més del teatre, Castelló comptarà també amb uns espais molt importants: les societats instructorecreatives. Aquestes societats adquiriran un gran protagonisme ja que en molts casos eren les que complementaven l'escassa oferta del teatre públic.

Pel que fa a la música de saló, tot i la dificultat de trobar fonts en aquest sentit, tenim constància de la realització d'alguns concerts en cases privades. En aquest cas, interpretar i escoltar música era una de les activitats lúdiques que es realitzaven a primeres hores de la nit per part de la burgesia local.

Un altre dels espais públics que van dur a terme una activitat musical a la ciutat van ser els cafès. Cal remarcar la importància d'aquests locals ja que era un dels pocs on les classes menys benestants podien tindre accés a la música.

Finalment, ens trobem amb el passeig, que a més d'una activitat social era també un lloc físic on les diferents bandes de música militar o civils interpretaven concerts amb la funció d'amenitzar aquest esdeveniment social. 


\title{
BIBLIOGRAFIA
}

Aguilera, J. (2011): El nacimiento de la sociedad burguesa: Castellón, 1833-1843, Castelló de la Plana, Universitat Jaume I.

Alonso, C. (1997): Un espacio de sociabilidad musical en la España romántica: las sociedades instructorecreativas, dins Encina, M. i R. Sobrino (dir.)(1997): Sociedades Musicales en España, Madrid, Fundación Autor.

AviñoA, X. (2000): «II Àmbit de creació i consum», dins AviñoA, X. (dir.)(2006): Història de la música catalana, valenciana i balear: III Del Romanticisme al Nacionalisme, Barcelona, Edicions 62.

Carreras, R. (1920): «Crónicas y recuerdos del Castellón ochocentista», Boletín de la Sociedad Castellonense de Cultura I, Castelló de la Plana, Sociedad Castellonense de Cultura.

Casares, E. (1995): «La Música del siglo xix español. Conceptos fundamentales», dins Casares, E. i C. Alonso (1995): La música española en el siglo XIX, Gijón, Colección Estudios Sociales Iberoamericanos, Universidad de Oviedo.

Chust, M. (1998): «La época contemporánea. La ciudad de Castellón durante el siglo XIX », dins OrTells, V. (dir.)(1998): La ciudad de Castellón de la Plana, Castelló de la Plana, Excmo. Ayuntamiento de Castellón de la Plana.

FERrer, I. (2012): «Passejos, pistes i plaques: els balls a l'Horta Sud durant el primer franquisme», Quadrivium, 3, 2012, <http://www.avamus.org/revista_qdv/qdv_numero3_indice.html>.

Mundina, B. (1873): Historia, Geografía y Estadística de la província de Castellón, Castelló de la Plana, Imprenta Rovira Hermanos.

Olucha, F. (1986): «Unas notas sobre el Teatro Principal de Castellón», Castelló de la Plana, Estudis Castellonencs.

Ortells, V. (1999): «Geografía comarcal», dins Gimeno SAnfeliu, M.J. (dir.)(1999): La provincia de Castellón, Castelló, Diputació de Castelló.

Plantinga, L. (1992): La música romántica, Madrid, Akal.

Ruiz de Liory, J. (1903): La música en Valencia. Diccionario Biográfico y crítico, València, Establecimiento Tipográfico Doménech.

SolÀ-Morales, I. (1984): «L'arquitectura teatral» dins Arquitectura Teatral en España, Madrid, Dirección General de Arquitectura y Vivienda, MOPU.

VIDAL, E. (dir.)(1996): Guia d'arquitectura, Castelló, Servei de publicacions de la Diputació de Castelló. Vidal, A. i V. Torrent (2006): «Sociedades Musicales», dins Casares, E. (dir.)(2006): Diccionario de la música valenciana, Madrid, Iberautor Promociones Culturales.

\section{HEMEROTECA ARXIU MUNICIPAL DE CASTELLÓ}

\author{
Alborada, La \\ Hermano Bartolo, El \\ Centinela, El \\ Centinela Federal, El \\ Crónica de Castellón, La \\ Diario de Castellón \\ Eco de Castellón, El \\ Faro, El \\ Revista Castellonense \\ Revista Castellonense, La \\ Voz, La \\ Voz del Pueblo, La
}




\section{BIONOTA}

\section{Ramon Canut Rebull}

Llicenciat en Història i Ciència de la Música per la Universitat Autònoma de Barcelona i Professor Superior de Saxofon. Funcionari de carrera del cos de Professors de Secundària, especialitat de Música. Diploma d'Estudis Avançats, actualment realitza la tesi doctoral sobre la vida musical castellonenca en la segona meitat del segle XIX. Ha publicat els articles: La difusión de la música escénica en Castellón de Plana (1850-1880): La importancia de las sociedades instructorecreativas (Congrés Internacional Ruperto Chapí); El fonògraf en València: 1898-1902 (Quadrivium); Al Tall i la renovació de la música tradicional valenciana (Biblioteca Virtual Miguel de Cervantes). Ha participat com a ponent en les Jornades sobre el Patrimoni Immaterial Valencià (Universitat Jaume I), Al Tall, 35 anys. Música valenciana i mediterrània de base tradicional (Universitat d'Alacant) i en les VIII Jornades de Musicologia (Associació Valenciana de Musicologia). 